NOTAS Y COMENTARIOS

\title{
POR UNA TEORfA DE LA RESPUESTA ESTÉTICA
}

\author{
por Gerardo del Rosal Vargas
}

Sólo en contadas ocasiones, por lo menos hasta hace unos veinte años, se habíx tomado en cuenta al lector al formular teorías acerca de la literatura. En muchas de ellas exclusivamente se prestaba atención a la intención del autor, al significado psicológico, sociológico o histórico de la obra, o a la estructura de la misma. Las pretensiones cientificistas estigmatizaron, durante algún tiempo, todo aquello que implicara subjetividad. El lector era sólo el último eslabón de un proceso social, un consumidor. Por ello se suponía que el autor únicamente lo consideraba como destinatario en el que debía despertar curiosidad. Al seleccionar el tema y la manera de exponerlo, el escritor tendría en mente la curiosidad del lector. Pero para analizar la obra, el lector no era un elemento pertinente. Constituia un factor extraliterario.

Actualmente, en cambio, se tiende a pensar que una teoría literaria empíricamente adecuada debe tener por lo menos dos componentes principales: "una teoría de los textos literarios y una teoría de la comunicación y contexto literarios". ${ }^{1}$ Se siente la necesidad de insertar en el contexto más. amplio del nivel pragmático el estudio de las estructuras que constituyer un texto. La obra, de esta manera, ya no es el único foco de atención. También hay que tener en cuenta las relaciones que existen entre el signo $y^{-}$ los usuarios. La teoría de la recepción literaria, por ejemplo -surgida en la "Escuela de Constanza"-, se propone estudiar el problema de la relación comunicativa entre un sujeto y el objeto artístico, más concretamente, entreel público y la obra literaria. Para este propósito, investiga la manera comohan acogido, leído y criticado algunas obras literarias lectores de épocas, países y clases sociales diferentes. Otro intento por resolver este problema lo representa la teoría de la respuesta estética, ${ }^{2}$ modelo propuesto por Wolfgang Iser. Las indagaciones teórico-literarias de este crítico alemán se apoyan en: la fenomenología husserliana y en las ideas de Roman Ingarden acerca de la concreción y reconstrucción de la obra literaria.

En este caso sólo me concretaré a analizar la relación que existe entre el

1. Teun A. van Dijk, Estructuras y funciones del discurso literario, p. 117.

2 El término alemán "Wirkung" tiene las acepciones de "efecto" y "respuesta". Para no crear confusión, en este texto emplearemos el término "respuesta". El lector, empero,. debe tener en mente que esta respuesta no es independiente de la obra, sino que es pro-ducto de un efecto. 
texto y el proceso de recepción. Para ello me basaré en el modelo teórico propuesto por W. Iser. Básicamente me ceñiré a lo expuesto en su libro Der Akt des Lesens. Theorie äesthetischer Wirkung, publicado en $1976 .^{3}$

Esta teoría, aunque muy ligada a la teoría de la recepción, difiere de esta última significativamente. Ambas analizan el efecto que produce la obra literaria en el lector. Pero la teoría de la respuesta estética no parte de las reaciones conocidas, sino que trata de establecer especulativamente una fenomenología de la lectura.

El punto de partida de esta teoría lo constituye la concepción del fenómeno literario como un proceso de interacción entre texto y normas históricas por una parte, y entre texto y disposición potencial del lector, por la otra. Así pues, no se analiza exclusivamente el texto, sino toda la situación comunicativa. El texto es un conjunto de aspectos esquematizados que debe concrecionar el lector. El significado no es algo observable en el texto, sino algo que se hace presente a través de la experiencia de la obra literaria. Surge de la interacción entre texto y lector. No se trata, empero, de una relación del tipo sujeto-objeto. La obra literaria es demasiado compleja como para que el receptor la pueda abarcar. De la misma forma en que el autor no puede recurrir a todas las tradiciones literarias ni a todas las normas históricas y sociales de que dispone -simplemente porque la memoria humana es limitada-, el lector tampoco puede agotar toda la información que el texto pone a su disposición. Es obvio, pues, que ambos participantes de este proceso comunicativo realizan una selección de entre diversas posibilidades. Esquemáticamente podemos representar este proceso de la manera siguiente:

\begin{tabular}{|c|c|c|c|c|c|c|}
\hline Repertorio & $\begin{array}{l}\text { Proceso } \\
\text { creativo }\end{array}$ & Texto & & & $\begin{array}{c}\text { Proceso } \\
\text { de } \\
\text { lectura }\end{array}$ & $\begin{array}{cc} & \text { Respuesta } \\
\text { Repertorio estética }\end{array}$ \\
\hline $\begin{array}{l}\text { Conjunto de } \\
\text { normas his- } \\
\text { tóricas, tra- } \\
\text { diciones lite- } \\
\text { rarias. }\end{array}$ & & $\begin{array}{l}\text { polo } \\
\text { artístico }\end{array}$ & texto & $\begin{array}{l}\text { polo } \\
\text { estético }\end{array}$ & & $\begin{array}{l}\text { Conjunto de } \\
\text { normas his- } \\
\text { tóricas, tra- } \\
\text { diciones lite- } \\
\text { rarias. }\end{array}$ \\
\hline
\end{tabular}

De esto se desprende que la lectura no es un proceso pasivo; implica actividad mental por parte del receptor. ¿Cómo articula éste un significado, cómo logra dar coherencia a esa serie de aspectos esquematizados?, son preguntas a las que intenta responder esta teoría de la respuesta estética.

Puesto que el proceso de la lectura implica intervención activa del lector,

3 nebo aclarar que no consulté el texto original, sino la traducción inglesa, The Act of Reading. A Theory of Aesthetic Response, Baltimore, The Hopkins University Press, 1978. 
el resultado de dicho proceso, el texto que articula el lector, no puede ser idéntico al texto impreso en el papel. De igual manera, este texto no es igual al del autor. La intención del autor en múltiples ocasiones es diferente al efecto que produce su obra. Cabe distinguir en el texto un polo artístico (el texto del autor), un polo estético (texto articulado por el autor), y en el centro el texto en sí, una entidad virtual y dinámica. Iser aplica al discurso literario las distinciones que J. Austin establece a nivel de actos de habla. El texto en sí constituye una noción paralela al acto locutivo; el polo artístico, al igual que el acto ilocutivo, refleja el énfasis en el emisor; y el polo estético, como el acto perlocutivo, surge al visualizar el acto comunicativo desde el punto de vista del receptor.

El crítico literario no puede analizar exclusivamente uno de estos aspectos, si pretende una visión integra del fenómeno literario. El lector constituye un tema ineludible ya que es él quien transforma en "realidad" la virtualidad de la obra literaria. En términos generales se podría decir que el lector está presente en la obra por el simple hecho de que ésta se compone de signos que pertenecen a un sistema sémico con valor social. En un plano más específico, podemos afirmar que el lector abre la posibilidad de una experiencia estética.

Aceptar que la obra literaria depende del lector para su concreción, no significa caer en un subjetivismo absoluto. La respuesta del lector está determinada por el texto mismo.

...toda obra, además de transmisora de determinados mensajes, es, a la vez, vehículo de una serie de inducciones de actitudes en el lector, es decir, intenta promover, en él, determinadas disposiciones de clases de respuestas, al mismo tiempo que descarta otras. ${ }^{4}$

Se considera a la obra literaria como un conjunto de instrucciones para producir significados. Dado este enfoque resulta imposible hablar de el significado de una obra literaria. Diferentes tipos de concreción lógicamente darán por resultado significados diferentes.

Como se ha dicho ya, la comprensión depende de la interacción entre texto y lector. Conviene aclarar que no se trata de un lector físico determinado, sino de un constructo teórico que permite describir la manera como las estructuras textuales pasan a formar parte de la experiencia de un individuo: el lector implícito. Puesto que se halla a la mitad del camino entre el texto y el receptor, en el lector implícito podemos distinguir dos aspectos. Por una parte, es una estructura textual, y por otra, se trata de un acto estructurado. En el primer caso se lo considera como el rol que el texto mismo le asigna. Es decir, toda obra presupone la intervención del lector, pues este último es quien formula un significado. En el segundo caso, se alude a lo "realizado" por el lector implícito.

El rol del lector implícito está determinado por tres componentes textuales. Lo delimitan las diferentes perspectivas presentes en el texto. (En una

4. Maldavsky, Teoria literaria general, p. 42. 
novela suele haber cuatro perspectivas: la del narrador, la de los personajes, la del argumento y la del lector.) También está determinado por el punto en que él mismo les haga converger. $Y$ por el punto en donde convergen. Como puede verse, la articulación de un significado depende de la interacción de elementos textuales y de decisiones subjetivas.

Para realizarse satisfactoriamente, todo proceso comunicativo requiere, entre otras condiciones, que los interlocutores compartan las mismas convenciones. En el proceso de comunicación literaria, el repertorio responde a dicha necesidad referencial. Funciona como el punto de contacto entre lector y texto, que permite al lector asimilar una experiencia ajena. Básicamente el repertorio hace alusión a normas históricas o sociales y a tradiciones literarias. En otras palabras, en el concepto de repertorio se trata de englobar todo el acervo de conocimientos y experiencias que puede tener un autor o un lector. Incluye el mundo extratextual y las convenciones socioculturales, así como el contacto con obras anteriores. Esto no significa que el mundo fictivo ${ }^{5}$ sea el mismo de la realidad extratextual, pues es bien sabido que el autor no vierte en la obra literaria todo ese cúmulo de conocimientos y vivencias. En la base del proceso creativo se halla un principio de selección, un valor estético. Al seleccionar uno de esos elementos, el autor lo saca de su contexto, lo depragmatiza y le confiere un nuevo valor. En este sentido se puede decir que el texto surge de la recodificación de normas históricas y de tradiciones literarias.

EI repertorio alude a esquemas conocidos, crea una especie de trasfondo contra el cual se provecta el significado del texto. Lo cual no implica que la obra cumpla una función referencial, es decir, que la realidad literaria sea un simple reflejo de la realidad extratextual. Esta última es, más bien, el punto de partida para la creación de una realidad nueva.

El proceso selectivo que da lugar a la producción literaria, lógicamente implica el rechazo de gran cantidad de información que el lector, de alguna manera, debe recuperar para poder concrecionar el significado de la obra. Los elementos ausentes constituven, en este sentido, recursos sionificantes. Sin embargo, la información recuperada por el lector no puede ser la misma que rechazó el autor. Ambas informaciones estarán inficionadas por virus subjetivos diferentes. Si se toma en consideración, por otra parte, que el signo lingǘstico sólo cobra valor comunicativo al entrar en relación con un contexto, las diferencias contextuales de ambos interlocutores también van a determinar la respuesta estética de cada uno de ellos. Por consiguiente, la respuesta estética no está garantizada exclusivamente por el material lingüístico de la obra. De ahí que un análisis de la representación discursiva no baste para dar cuenta del fenómeno literario.

Como ya se señaló, el repertorio no aparece integramente en el texto - de ser así la obra literaria se convertiría en un documento-, sino que es filtrado por las estrategias que emplea el autor. El concepto de "estrategias" denota la manera como el autor organiza en la obra la concreción

5 Preferimos el término "fictivo" para evitar la connotación de "contrario a la realidad" presente en el vocablo "ficticio". 
del contexto referencial aludido por el repertorio. Puesto que organizan el material del texto, también establecen las condiciones en las que va a ser comunicado. Pero el hecho de que la presentación esté organizada no elimina la posibilidad de selección del lector. Sólo le ofrece posibilidades de organización. La función pragmática de las estrategias es hacer desconocido lo conocido. Las normas de la lengua natural y los cánones estéticos son reestructurados en la obra literaria. Al relacionar lo expuesto en la obra literaria con el contexto referencial, el lector percibe los significados de la obra en los puntos en que la primera se aleja, se desvía del segundo. El significado, empero, no surge por la desviación, sino gracias a la relación de ambos elementos.

En términos más específicos, las estrategias representan la manera como el autor combina las diferentes perspectivas para crear un sistema interno de referencias que preestructuren las posibles formas del objeto estético que va a producir el lector. Así pues, el lector no puede establecer relaciones entre cualquiera de las perspectivas, sino sólo entre aquellas en las que existe una correlación potencial. Sin embargo, es el lector quien otorga valor a dicho sistema. Para tal efecto se basa en la manera como el repertorio se haya distribuido entre las perspectivas. El valor significativo de un elemento seleccionado depende, en parte, de si lo expresa el narrador, el personaje principal o un personaje secundario, del lugar que ocupe en el desarrollo del argumento, etcétera.

Puesto que no puede captar de un solo vistazo la obra íntegra, sino que la aprehende en una serie de momentos sucesivos, el lector percibe las estrategias como una estructura secuencial de "tema" y "horizonte". Tema es la perspectiva que adopta el lector en un momento determinado y que tiene como trasfondo el horizonte de las otras perspectivas. El horizonte está compuesto por los temas de momentos de lectura anteriores. Cada segmento se hace realidad por oposición a los demás. Refleja e ilumina las otras. La estructura de tema y horizonte responde al sistema de perspectivas que surge de la linealidad esencial del texto. Dicha estructura organiza, entonces, la relación del lector con el texto, y, por ende, sus actitudes.

Sin embargo, el lector no es un interlocutor pasivo ante cuya mirada desfilan series de perspectivas. El punto de vista del lector se caracteriza por ser móvil. En cada momento de lectura se sitúa en una perspectiva determinada, pero no está restringido a ella. Esta movilidad le permite descubrir la multiplicidad de perspectivas virtualmente interrelacionadas. La formulación de equivalencias significativas es privilegio del lector. La conexión de perspectivas, por ende, depende de factores subjetivos tales como memoria, interés, atención y capacidad mental.

Este concepto del punto de vista móvil permite la fragmentación del texto en grupos de estructuras interactuantes. Actividad fundamental para la comprensión. Cada correlato oracional -parte del texto que puede ser abarcado en un momento de lectura- predetermina una visión específica que se convierte en trasfondo del siguiente. En cada correlato se puede distinguir un juego de fuerzas en dirección contraria. Responde a expectativas 
suscitadas por correlatos anteriores, pero al mismo tiempo provoca otras. Añade información a aspectos mencionados con anterioridad y apuntan hacia otros que no se han resuelto. La lectura, en este sentido, es un proceso dialéctico.

Dada la naturaleza lineal del texto, al lector le corresponde dar una interpretación coherente a la serie de correlatos oracionales que lo constituyen. Para lograrlo, primero elabora una interpretación inicial, abierta. Por lo general surge de la interacción entre personaje y argumento. Posteriormente formula otra interpretación que delimite la primera. En otras palabras, el lector teje una red de conexiones posibles y escoge uno de esos hilos. Esto no implica que las posibilidades descartadas desaparezcan. Continúan bombardeando las interpretaciones formuladas y las modifican. En este proceso de interpretación intervienen decisivamente las estrategias textuales, ya que pueden eclipsar algunas posibilidades virtuales o aumentar la fuerza de otras de ellas.

La comprensión del texto demanda una gran actividad por parte del lector. Dicha interacción es de tal naturaleza que el producto del proceso de lectura es distinto del resultado del proceso creativo. A partir de esta diferencia es factible distinguir entre significado y significación. El significado es el conjunto de referencias que se encuentra implícito en los aspectos textuales y que debe ser articulado en el proceso de lectura. La significación, en cambio, alude al significado que el lector adopta para su propia existencia. Constituyen realidades tan autónomas que el hecho de que se haya captado un significado, no es garantía de que se posea una significación. Esto permite explicar por qué dos intérpretes pueden tener dos opiniones totalmente distintas, e incluso opuestas, aunque partan del análisis de los mismos aspectos textuales.

La interacción que ocurre durante el proceso de la lectura, no es igual a la interacción lingüística que se da en la lengua natural. En la interacción cara a cara los interlocutores pueden hacerse preguntas para averiguar hasta qué punto sus imágenes corresponden a la experiencia ajena que las originó. Esto no se da en la comunicación literaria. El lector no puede saber qué tan exactos son sus enfoques. La imposibilidad de comprobación matiza la interacción literaria. La falta de contacto inmediato, por otra parte, impide a cada participante predecir la conducta del otro. Dicha impredictibilidad obliga a los interlocutores a aventurar series de interpretaciones y a realizar ajustes estratégicos y tácticos a cada momento.

Puesto que no puede recurrir al emisor para recuperar la información ausente, el lector bombardea con proyecciones los puntos de indeterminación presentes en el texto. Estas proyecciones, aunque subjetivas, no pueden ser arbitrarias ya que tienen que estar adaptadas al texto. Las modificaciones están determinadas por el texto también. De esta manera surge un marco de referencia común que posibilita la interacción comunicativa.

Las estructuras de indeterminación pueden ser de dos tipos: los espacios en blanco y las negaciones. Los primeros amplian las posibilidades de relación entre las perspectivas. Las segundas, en cambio, evocan elementos cono- 
cidos sólo para invalidarlos. Ambas estimulan y encauzan el proceso de ideación.

Los espacios en blanco señalan en el texto puntos donde se ha roto la relación de elementos textuales. En la obra literaria se perciben como abruptas yuxtaposiciones de segmentos. Interrumpen el orden que esperábamos encontrar en el desarrollo del argumento. En otras palabras, destruyen expectativas y suscitan otras. Al suspender la continuidad condicionan el choque de imágenes en la mente del lector y por consiguiente obstaculizan el proceso de ideación. De esta manera se crea una distancia básica para la comprensión.

Conviene aclarar que los espacios en blanco no hacen referencia a la omisión de elementos temáticos. Equivaldría a aceptar que la realidad literaria no es completa. Lo que hace falta no es completar, sino relacionar. En esto se distinguen del concepto de "puntos de indeterminación" propuesto por Roman Ingarden. Los puntos de indeterminación aluden a lagunas temáticas en el texto. Los espacios en blanco, en cambio, sólo indican que se deben relacionar segmentos textuales. Las relaciones que establezca el lector lógicamente están determinadas por una previa selección personal. De ahi que también obliguen al lector a introducirse en el texto. (Esto no debe considerarse como contradicción de lo dicho en el párrafo anterior. Lo que sucede es que en el proceso de lectura continuamente se da este movimiento en direcciones opuestas.) Los espacios en blanco no sólo ocurren entre perspectivas diferentes, también se dan en los segmentos de una misma perspectiva. Sin embargo, el lector no puede establecer cualquier tipo de relación entre los segmentos. Para llenar espacios en blanco el lector debe guiarse por el archisema -elemento que subyace a los segmentos desconectados y que, una vez descubierto, los agrupa en una nueva unidad de significado.

Así pues, el espacio en blanco permite organizar el texto en campos referenciales, actividad básica para el proceso de comprensión. Un campo referencial se forma cuando se interrelacionan por lo menos dos segmentos textuales, y constituye la unidad mínima de comprensión. Una vez descubierta la "conectabilidad" de varios segmentos, el espacio en blanco, como marco de referencia no formulado, posibilita la formulación de una relación determinada entre ellos. Este campo referencial surge porque la estructura de "tema-horizonte" obliga al punto de vista del lector a pasar de una perspectiva a otra. Sin embargo, no debemos olvidar que la percepción del tema está condicionada por el horizonte de las perspectivas anteriores. Y como el lector no puede recordar íntegramente todos los segmentos textuales anteriores, en el "horizonte" también hay puntos indeterminados: espacios vacíos. Los espacios vacíos, por tanto, condicionan la interpretación del "tema" nuevo.

Otro elemento textual que condiciona el proceso de ideación del lector es la negación. Las negaciones reducen, en vez de ampliar, la conectabilidad de los segmentos. Suscita imágenes mentales en el lector y las destruye. Al invalidar ciertas actitudes del lector, indirectamente le indica posibles 
rumbos a seguir. Además, conducen al lector a tomar conciencia de la orientación que está recibiendo. Le recuerdan que la obra no es un pretexto para echar a volar su imaginación. Las negaciones, empero, no sólo invalidan posiciones del lector, también pueden afectar a normas socioculturales y cánones estéticos, es decir, al repertorio.

Así pues, la comunicación literaria no está regulada por ningún tipo de código preestablecido. Se trata, más bien, de un proceso determinado por lo que se revela y lo que se esconde, por lo explícito y lo implícito. Ello exige del receptor capacidad para comprender de manera clara y diferenciada un número indeterminado de relaciones - dentro del texto mismo, del texto con la realidad extratextual, y del texto con el lector- portadoras de significado. Además, el lector debe ser capaz de percibirse a sí mismo como receptor durante el proceso de interpretación. Para que se produzca la experiencia estética no basta que el lector esté consciente de la experiencia, también tiene que cobrar conciencia de los medios a través de los cuales se da. El texto es una entidad virtual que contiene series de instrucciones para la producción de un significado. El significado no es algo dado por la obra, sino una experiencia que se produce en la mente del lector. Lógicamente, entonces, al crítico no le corresponde explicar una obra, sino revelar el potencial significativo de un texto, aclarar las condiciones que hacen posible la producción de diferentes respuestas. Una de las ventajas de este tipo de análisis es que proporciona un marco de referencia para valorar respuestas individuales diferentes a un mismo texto.

Puede objetarse -ya lo han hecho algunos críticos- que esta teoría concede demasiada importancia al lector y descuida al texto. Esta objeción es cierta, pero me parece que en esta desviación de los criterios usuales radica el valor de la teoría misma. Al profundizar en aspectos que han sido descuidados por otras teorias, enriquece nuestro conocimiento de la comunicación literaria. Por otra parte, los conceptos que aventura suscitan cuestionamientos, abren nuevos campos de indagación. Corresponde a otros estudiosos de la literatura comprobarlos o invalidarlos.

Otra objeción que se ha hecho gira en torno a la aplicabilidad de la teoría. Se le acusa de que sólo es aplicable a cierto tipo de textos. Esto es cierto, pero también es cierto que las otras teorías son inaplicables a este tipo de textos. Significativamente, sin embargo, día con día aumenta el número de textos a los que se puede aplicar. Lo cual implica que los criterios de la producción literaria contemporánea están mejor captados por esta teoría.

Por último, también se le acusa de postular un lector muy especializado. A mi vez, yo preguntaría, ¿cualquier lector es capaz de digerir una obra como el Ulises de Joyce?

\section{BIBLIOGRAFIA}

Julio de 1982.

Iser, Wolfgang, The Act of Reading, Baltimore, The John Hopkins University Press, 1978. Maldavsky, D., Teoria literaria general, Buenos Aires, Ed. Paidós, 1974.

van Dijk, Teun A., Estructuras y funciones del discurso, México, Siglo XXI Editores, 1980. 